\title{
Assessment of the Impact of Energy-Saturated Tractor Movers on Soil
}

\author{
Alexey V. RUSINOV \\ Ph.D. in Engineering \\ Associate Professor \\ Department of Technosphere Safety and Transportation Technology Machines \\ Faculty of Engineering and Environmental Engineering \\ Saratov State Agrarian University named after N. I. Vavilov \\ 60, Sovetskaya Str., Saratov, 410056, Russia

\section{Dmitriy A. RYBALKIN} \\ Ph.D. in Engineering \\ Associate Professor \\ Department of Technosphere Safety and Transportation Technology Machines \\ Faculty of Engineering and Environmental Engineering \\ Saratov State Agrarian University named after N. I. Vavilov \\ 60, Sovetskaya Str., Saratov, 410056, Russia
}

\section{Dmitry A. RUSINOV}

Student

Faculty of Systems for Providing Train Traffic

Samara State University of Railway Engineering

$181^{\text {st }}$, Bezymyanny Lane, Samara, 443066, Russia

\begin{abstract}
Implementation of agricultural technologies for crop cultivation is not possible without the use of energy-saturated tractors. As a result of the passage of tractor movers, they have a negative effect on the soil, leading to its compaction and lower crop yields. The aim of the research is to determine the influence of movers of various running systems of energy-saturated tractors on the physical and mechanical properties of the soil. To assess the impact of tractor movers on the soil, mathematical dependencies were presented to determine the soil index characterizing the physical and mechanical property of the soil, which is changed as a result of the impact and its influence when assessing the complex indicator of soil impact. The results of field studies of the effects of movers of the tractors K-701 and K-744 on the soil are presented. As a result of the research, it was found that the serial single mover of an energy-saturated tractor exerts a strong effect on the soil, creating a high voltage
\end{abstract}


in it leading to excessive soil compaction. The use of double wheels in comparison with single wheels makes it possible to reduce the negative impact on the soil; in particular, a decrease in stresses occurring in the soil to $10.1 \%$ and a decrease in soil density along the tracks of movers to $13.8 \%$ were recorded. The results of the calculation of a comprehensive indicator of the negative impact on the soil by different tractors are presented. The proposed methodology allows optimal manning of the enterprise's vehicles providing minimal impact on the soil and crop preservation.

Keywords: energy-saturated tractor; impact on the soil; soil compaction.

\section{Introduction}

Growing crop products and meeting the requirements of agricultural technologies for their cultivation are not possible without the use of machine-tractor units based on energy-saturated tractors. The advantages of energy-saturated tractors are great traction, good maneuverability and high productivity; however, mass of tractors produced in Russia and foreign countries has increased significantly in recent years (Keller et al., 2019). Currently there are widely used energy-saturated tractors "Kirovets" (K-701, K-744P) in the Saratov region, the mass of these tractors exceeds 13 tons. When the tractor moves across the field, due to the large mass, high contact pressures are created under the wheeled undercarriage, which leads to soil deformation and compaction. As a result of soil compaction along the trail of tractor wheels, soil structure changes, its porosity decreases, water-air and thermal conditions of the soil are disturbed, density increases, which ultimately leads to a decrease in crop yield. It was established that the optimal soil density for normal growth and development of an agricultural plant is $1.1-1.3 \mathrm{~g} / \mathrm{cm}^{3}$ (Konishchev et al., 2019; Szatanik-Kloc et al., 2018), and after the passage of a wheeled tractor its value in the tracks reaches 1.4-1.6 g/cm³ (Szatanik-Kloc et al., 2018; Bogunovic et al., 2017). An increase in density above the optimum by $0.1 \mathrm{~g} / \mathrm{cm}^{3}$ leads to a deterioration in plant growth and a decrease in the yield of grain crops to $12 \%$ (Slyusarenko et al., 2016). Performing the full cycle of operations of the applied agricultural technology, movers of energy-saturated tractors subject more than half of the field area to over-compaction, which negatively affects the yield and profit of the enterprise. In this regard, the question arises of the need to reduce the negative impact of wheeled energy-saturated tractors on the soil.

\section{Methods}

The aim of the research is to determine the influence of propulsion systems of various running systems of energy-saturated tractors on the physical and mechanical properties of the soil (density as the main compaction parameter). Research was conducted on the fields of the Novouzenskiy district of the Saratov region. Soil type is heavy loam. In the course of the research, the serial layout 
of the movers of the tractors $\mathrm{K}-701$ and $\mathrm{K}-744 \mathrm{P}$ and the chassis system with dual tires were considered.

In particular, along the passage tracks of the tractor movers, there were measured the stresses occurring in the soil during the passage of the mover, as well as residual consequences in the form of changes in the density and hardness of the soil. Measurement of stresses was carried out by the method of strain gauging with the help of DPU sensors, on which a sensitive element was installed (Buylov et al., 2020). The sensors were previously laid in the soil at different horizons from 0 to $100 \mathrm{~cm}$ and connected to the strain gauge station MIC-018.

Measurement of soil density after the passage of tractor movers was carried out using the cutting cylinder method. The method is based on the introduction of a predetermined volume of a cutting cylinder into the soil with subsequent soil extraction and weighing.

\section{Literature Review}

The problem of negative impact of the energy-saturated tractor movers on the soil is valid not only for Russia, but also for a number of foreign countries with developed agricultural production. The recorded constant increase in the mass of tractors (Keller et al., 2019) causes excessive soil compaction, exceeding the permissible values, which leads to a decrease in the yield of agricultural crops.

Lamandé and Schjønning (2018) note that an increase in the mass of the axis of the moving wheel in the soil leads to an increase in stresses created in the soil. The resulting stresses have values that exceed the bearing capacity of the soil, which causes its deformation and compaction. A similar situation was noted for caterpillar movers (Mudarisov et al., 2020).

In addition to the mass attributable to its axis, the internal air pressure in the tire also affects the increase in soil density after the passage of the tractor movers. Holthusen et al. (2018) prove that increasing air pressure in a tire leads to an increase in soil density along the tracks of tractors and combines. Reducing the air pressure in the tire helps to increase the bearing area of the wheel and reduce soil compaction.

Undoubtedly, an increase in soil density contributes to a decrease in crop yield. So, Szatanik-Kloc et al. (2018) proved that increasing the density of the soil from $1.29 \mathrm{~g} / \mathrm{cm}^{3}$ to $1.61 \mathrm{~g} / \mathrm{cm}^{3}$ reduces the development of the root mass of plants and, as a result, the development of the plant itself due to lack of nutrients.

The process of compaction of the soil is aggravated by numerous passes of energy-saturated tractors across the field as a result of the implementation of a full cycle of agricultural cultivation 
technology. The authors of the studies (Obour et al., 2017; Obour et al., 2018; Silva et al., 2018) note that soil compaction depends on the timing and time of tillage operations, while soil compaction reaches the lower layers to a depth of $1 \mathrm{~m}$.

To implement the research, the above authors developed and presented a methodology for determining the degree of influence of the parameters of tractor propulsion on the soil compaction process. The considered methods well describe only the process of compaction of the soil by tractor engines under the considered conditions presented by the authors. But with changing soil and tractor operating conditions, the proposed methods require adjustment and further study.

\section{Results}

To determine the complex degree of negative impact of the movers of energy-saturated tractors on the soil, we propose to make a general assessment of the changes in the physical and mechanical properties of the soil as a result of this effect. This is possible if there is measurement of changes in the indicator of the soil reflecting its physical and mechanical property, taking into account the impact of the tractor movers on the soil. The proposed methodology for assessing the impact of tractor movers on the soil is based on the fact that the soil has the initial value of the physical and mechanical property indicator before the onset of action and its increase after the tractor mover is exposed. Then this condition can be written as:

$$
\Pi_{\mathrm{ki}}=\frac{\Pi_{\mathrm{ci}}^{\max }-\Pi_{\mathrm{cд}}}{\Pi_{\mathrm{ci}}^{\max }-\Pi_{\mathrm{ci}}^{\min }},(1)
$$

where $\Pi_{\mathrm{ci}}^{\max }$ - the maximum value of the soil indicator, which can be reached as a result of the mover impact; $\Pi_{\text {сд }}$ - the absolute indicator of soil properties taken as permissible; $\Pi_{\mathrm{ci}}^{\min }$ - the minimum value of the soil indicator, as a rule, the reference value before the onset of exposure.

The indicator can be any physical and mechanical property of the soil, which can be measured before and after the passage of the mover of the tractor. As indicators of the soil can be selected density, hardness, deformation, porosity and macro-aggregate composition of the soil. They are fairly easy to measure; they are indirectly related to each other and the stresses arising in the soil during the movement of the tractor wheel.

Having determined the values of one and the same indicator of soil obtained under the influence of different tractors and their running systems, it is possible to conduct a comparative analysis and assess the degree of influence of each tractor on the soil. At the same time, the values recommended by leading scientists or regulated by GOSTs can be taken as an absolute indicator of soil properties. 
IV International Scientific and Practical Conference "Modern S\&T Equipments and Problems in Agriculture"

For example, the recommended values of stresses arising in the soil as a result of the passage of the tractor movers are recommended by GOST 26955-86 "Mobile agricultural machinery. Norms of mover influence on the soil".

The most common way to reduce the negative impact of wheeled tractor movers on the soil is to increase the contact area of the mover by installing additional wheels (doubling). To determine the degree of influence of a single and dual mover of the K-701 and K-744R tractor on the soil, we conducted studies to determine the stresses that occur in the soil during the movement of the mover. In the course of studies, it was established (Figure 1) that stresses equal to $225 \mathrm{kPa}$ - a single wheel and $148 \mathrm{kPa}$ - double wheels arise in the contact track of the wheel of the K-701 tractor with soil. The stresses in the contact point created by the single wheel of the K-744P tractor are by $6.1 \%$ less compared to the K-701 tractor, and for double wheels this parameter is lower by $7.2 \%$. An increase in depth leads to a decrease in the propagation of stresses arising in the soil during the passage of the K-701 and K-744P tractors with both single and double wheels (Figure 1). Comparing the results obtained, it can be seen that the stresses generated in the soil during the passage of the K$744 \mathrm{P}$ tractor with single wheels are on average by $10.1 \%$ lower compared to the stresses generated in the soil during the passage of the wheels of the K-701 tractor. A similar trend is observed with double wheels.

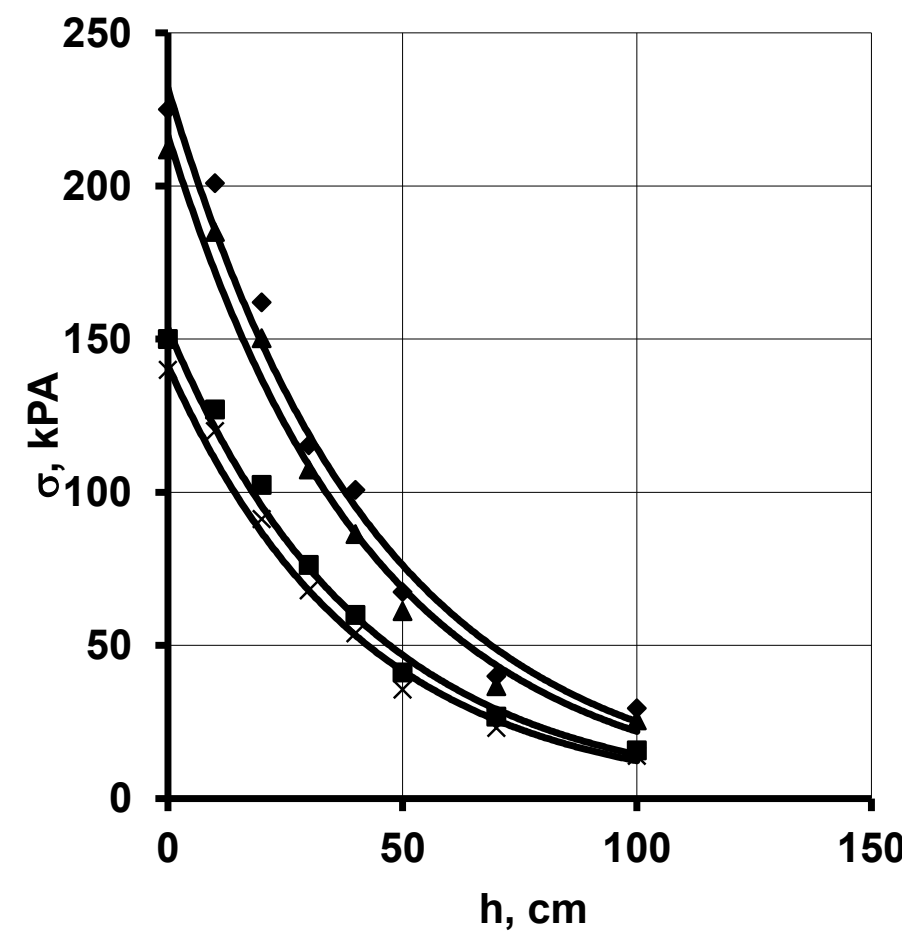

$$
\begin{gathered}
\sigma(1)=231,97 \mathrm{e}^{-0,0223 \mathrm{~h}} \\
\mathrm{R}^{2}=0,974 \\
\sigma(2)=216,4 \mathrm{e}^{-0,0229 \mathrm{~h}} \\
\mathrm{R}^{2}=0,9799 \\
\sigma(3)=153,5 \mathrm{e}^{-0,0237 \mathrm{~h}} \\
\mathrm{R}^{2}=0,9903 \\
\sigma(4)=147,5 \mathrm{e}^{-0,0259 \mathrm{~h}} \\
\mathrm{R}^{2}=0,9934
\end{gathered}
$$$$
\bullet(1) \mathrm{K}-701
$$

(2) K-701 double tires

$\Delta(3)$ K-744P1

$\times(4)$ K-744P1 double tires

Figure 1. Stresses occurring in the soil as a result of the passage of the K-70 and K-744P tractor movers 
Stresses generated in the soil and caused by the passage of the tractor wheels lead to soil deformation and compaction. Soil density is one of the main physical and mechanical properties of the soil that have a significant effect on the growth of agricultural plants. We conducted experiments on changes in soil density as a result of the passage of single and double wheels of the K-70 and K-744 tractors (Figure 2). In the course of measurements of soil density at different depths, it was found that the top soil layer of $0-10 \mathrm{~cm}$ is subjected to the greatest compaction. This is explained by good compressibility and deformability of clay soils, which include heavy loam. A further increase in soil depth indicates an increase in density for all types of running equipment of tractors. However, at a depth of 10-20 cm there is a slight decrease in soil density compared with the soil density of the upper horizon. This circumstance can be explained by the large involvement of soil volume in the compaction process and consciousness of the previously compacted soil layer in the upper horizon. Comparing the values of soil density after the passage of the single and double wheels of the K-701 and K-744 tractors, it can be noted that the soil density after the passage of the double wheels is by $13.8 \%$ lower on average compared to the density of the soil after the passage of a single wheel.

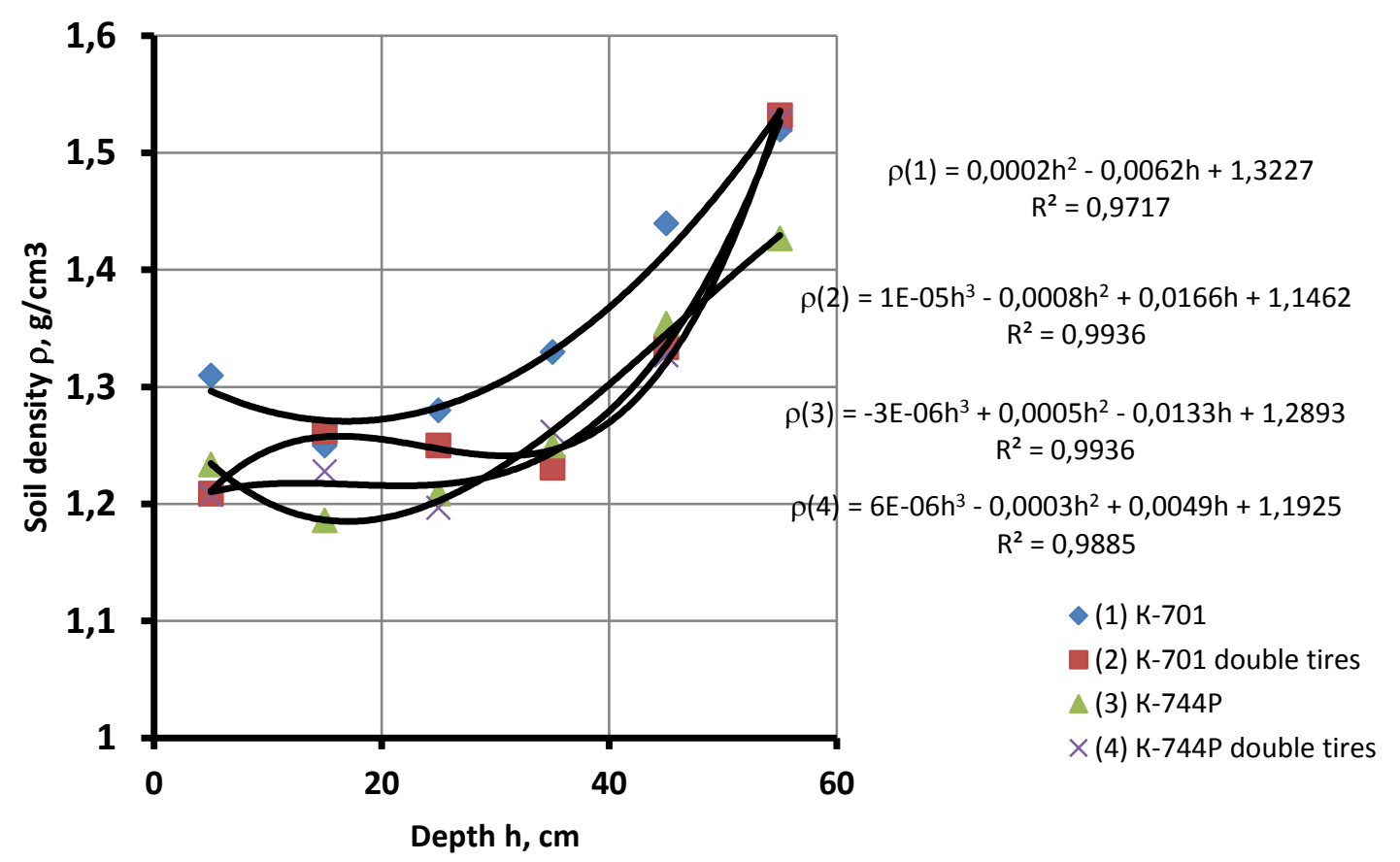

Figure 2. Change in soil density along the tracks of the K-70 and K-744P tractor movers

The conducted studies allow concluding that it is advisable to use double wheels on energysaturated tractors to reduce the negative impact on the soil.

However, technologies for growing crops involve performing many operations related to the passage of energy-saturated tractors across the field. Due to the equality or multiplicity of the width 
of the tillage units, the tractors repeatedly move along one track. The soil experiences repeated exposure to tractor running systems, which leads to an increase in indicators evaluating the degree of impact of tractor movers on the soil. It has been established that the soil is capable of accumulating negative effects from the tractor mover, while the accumulation of soil density is irreversible within one year. Based on these judgments, it is possible to record the change in the soil index taking into account the frequency of exposure, then:

$$
\Pi_{\Pi}=\Pi_{п к}-\left(\Pi_{п к}-\Pi_{п о}\right) \mathrm{e}^{-\mathrm{kn}}
$$

where $\Pi_{п к}-$ an indicator of the soil to which it tends with repeated exposure $n \rightarrow \infty ; \Pi_{п о}-$ value of the soil indicator without impact; $\mathrm{k}$ - a coefficient characterizing the accumulation of the soil index with repeated exposure to the soil.

An assessment of the complex effect of tractor movers on the soil is carried out with the determination of several indicators of the soil, while their size and significance for the growth of crops can be different. Then, taking into account the introduced weight coefficient of a single soil quality indicator, it is possible to assess the degree of impact of energy-saturated tractor movers on the soil by determining the complex indicator of soil impact determined by a mathematical model of the following form:

$$
\Pi_{\mathrm{k}}=\sum_{\mathrm{i}=1}^{\mathrm{n}} \frac{\Pi_{\mathrm{ci}}^{\max }-\Pi_{\mathrm{c}}}{\Pi_{\mathrm{ci}}^{\max }-\Pi_{\mathrm{ci}}^{\min }} \frac{\frac{1}{\Pi_{\mathrm{ki}}^{\max }-\Pi_{\mathrm{ki}}^{\min }}}{\sum_{\mathrm{i}=1}^{\mathrm{n}} \frac{1}{\Pi_{\mathrm{ki}}^{\max }-\Pi_{\mathrm{ki}}^{\min }}}
$$

Based on the mathematical model and determining the quality indicators of the soil as a result of the influence of the movers of different tractors, it was found (Table 1), that the DT-75 tractor with tracked running equipment has the least impact on the soil. Then the value of the DT-75 tractor complex indicator of the impact of the mover on the soil can be taken 1. For the remaining tractors, the value of the complex indicator of the effect on the soil or the degree of negative impact was calculated taking into account the indicators of the effect on the soil estimated by the created pressure in the soil as a result of the movement of the mover of the tractor and the consequences of its passage in increasing the density of the soil and the passage track.

Table 1. Change in soil quality indicators and a comprehensive indicator of the energysaturated tractor mover impact on the soil

$\begin{array}{ccccc}\text { Tractor brand } & \begin{array}{c}\text { Mover pressure on } \\ \text { the soil, } \mathrm{kPa}\end{array} & \begin{array}{c}\text { Density of the soil, } \\ \mathrm{g} / \mathrm{m}^{3}\end{array} & \text { Track depth, } \mathrm{cm} & \begin{array}{c}\text { Comprehensive } \\ \text { indicator of the } \\ \text { effect on the soil }\end{array}\end{array}$




\begin{tabular}{lcccc} 
МТ3-80 & 70 & $1.43-1.36$ & $6-8$ & 1.4 \\
\hline К-701, К-744P & 110 & $1.48-1.44$ & $7-9$ & 2.2 \\
\hline ДТ-75 & 50 & $1.4-1.36$ & $5-6$ & 1.7 \\
\hline MT3-1221 & 85 & $1.44-1.38$ & $6-7$ & 1.8 \\
\hline MT3-1522 & 90 & $1.45-1.39$ & $6-8$ & 1.9 \\
\hline PT-M-160 & 95 & $1.45-1.40$ & $7-8$ & 2.16 \\
\hline XT3-16331 & 108 & $1.47-1.43$ & $8-9$ & 2.4
\end{tabular}

\section{Conclusion}

The presented mathematical dependences and the results of the studies allow determining the degree of negative impact of the energy-saturated tractor movers on the soil. Focusing on the tractor with the least degree of impact of movers on the soil, it is possible to carry out the optimal selection of tractors and technical devices providing the least compaction of the soil and, as a result, preservation of the crop yield.

\section{References}

Bogunovic, I., Bilandzija, D., Andabaka, Z., Stupic, D., Comino, J. R., Cacic, M., Brezinscak, L., Maletic, E., Pereira, P. (2017). Soil compaction under different management practices in a Croatian vineyard. Arabian Journal of Geosciences, $10,340$. https://doi.org/10.1007/s12517-017-3105-y

Buylov, V.N., Lyulyakov, I.V., Pavlov, A.V., Rusinov, A.V., Mezhetsky, G.D. (2020). Identifying reasons for failure of soil processing units of working bodies. 6th International Conference on Agriproducts processing and Farming IOP Conference Series: Earth and Environmental Science, 422, 012116. https://doi.org/10.1088/1755-1315/422/1/012116

Holthusen, D., Reichert, J.M., Brandt, A.A., Horn, R., Fleige, H., Zink, A. (2018). Soil functions and in situ stress distribution in subtropical soils as affected by land use, vehicle type, tire inflation pressure and plant residue removal. Soil \& Tillage Research, 184, 78-92.

Keller, T., Sandin, M., Colombi, T., Horn, R., Or, D. (2019). Historical increase in agricultural machinery weights enhanced soil stress levels and adversely affected soil functioning. Soil \& Tillage Research, 194, 104293. https://doi.org/10.1016/j.still.2019.104293

Konishchev, A.A., Garifullin, I.I., Konishcheva, E.N. (2019). About the method of using the characteristics of "optimal density" in studies of soil cultivation. Vladimir farmer, 1(87), 16-20. (in Russian) 
IV International Scientific and Practical Conference "Modern S\&T Equipments and Problems in Agriculture"

Lamandé, M., Schjønning, P. (2018). Soil mechanical stresses in high wheel load agricultural field traffic: a case study. Soil Research, 56(2), 129-135. https://doi.org/10.1071/SR17117

Mudarisov, S., Gainullin, I., Gabitov, I., Hasanov, E., Farhutdinov, I. (2020). Soil compaction management: reduce soil compaction using a chain-track tractor. Journal of Terramechanics, 89, 1-12. https://doi.org/10.1016/j.jterra.2020.02.002

Obour, P.B., Kolberg, D., Lamandé, M., Børresen, T. (2018). Compaction and sowing date change soil physical properties and crop yield in a loamy temperate soil. Soil \& Tillage Research, 184, 153-163. https://doi.org/10.1016/j.still.2018.07.014

Obour, P.B., Schjønning, P., Peng, Y., Munkholm, L.J. (2017). Subsoil compaction assessed by visual evaluation and laboratory methods. Soil \& Tillage Research, 173, 4-14. https://doi.org/10.1016/j.still.2016.08.015

Silva, R.P.. Rolim, M.M., Gomes, I.F., Pedrosa, E.M.R., Tavares, U.E., Santos, A.N. (2018). Numerical modeling of soil compaction in a sugarcane crop using the finite element method. Soil \& Tillage Research, 181, 1-10. https://doi.org/10.1016/j.still.2018.03.019

Slyusarenko, V.V., Rusinov, A.V., Fedyunina, T.V. (2016). The influence of movers of machinetractor units on the crop yield. International Research Journal, 3-3(45), 120-122. (in Russian)

Szatanik-Kloc, A., Horn, R., Lipiec, J., Siczek, A., Szerement, J. (2018). Soil compaction-induced changes of physicochemical properties of cereal roots. Soil \& Tillage Research, 175, 226-233. https://doi.org/10.1016/j.still.2017.08.016 